Open Access

\title{
Active immunization against complement factor C5a: a new therapeutic approach for Alzheimer's disease
}

Christine Landlinger", Lisa Oberleitner, Petra Gruber, Birgit Noiges, Kristyna Yatsyk, Radmila Santic, Markus Mandler and Guenther Staffler

\begin{abstract}
Background: Alzheimer's disease (AD) is the most common neurodegenerative disease characterized by neuronal loss due to amyloid beta aggregations, neurofibrillary tangles, and prominent neuroinflammation. Recently, interference with neuroinflammation as a new therapeutic approach for AD treatment gained great interest. Microglia cells, one of the major contributors in neuroinflammation, are activated in response to misfolded proteins such as amyloid $\beta$ and cell debris leading to a sustained release of pro-inflammatory mediators. Especially, complement factor $\mathrm{C} 5 \mathrm{a}$ and its receptor have been found to be up-regulated in microglia in the immediate surroundings of cerebral amyloid plaques and blocking of $\mathrm{C} 5 \mathrm{aR}$ resulted in a reduction of pathological markers in a model of AD. Here, we investigate the effect of active vaccination against the complement factor $\mathrm{C} 5 \mathrm{a}$ to interfere with neuroinflammation and neuropathologic alterations in a mouse model of AD.
\end{abstract}

Methods: Short antigenic peptides AFF1 and AFF2, which mimic a C-terminal epitope of C5a, were selected and formulated to vaccines. These vaccines are able to induce a highly specific antibody response to the target protein C5a. Tg2576 mice, a common model of AD, were immunized with these two C5a-peptide vaccines and the induced immune response toward C5a was analyzed by ELISA and Western blot analysis. The influence on memory retention was assessed by a contextual fear conditioning test. Microglia activation and amyloid plaque deposition in the brain was visualized by immunohistochemistry.

Results: Both C5a-targeting vaccines were highly immunogenic and induced sustained antibody titers against C5a. Tg2576 mice vaccinated at early stages of the disease showed significantly improved contextual memory accompanied by the reduction of microglia activation in the hippocampus and cerebral amyloid plaque load compared to control mice. Late-stage immunization also showed a decrease in the number of activated microglia, and improved memory function, however, had no influence on the amyloid $\beta$ load.

Conclusion: C5a-peptide vaccines represent a safe and well-tolerated immunotherapy, which is able to induce a strong and specific immune response against the pro-inflammatory molecule C5a. In a mouse model of AD, C5a-peptide vaccines reduce microglia activation and thus neuroinflammation, which is supposed to lead to reduced neuronal dysfunction and $\mathrm{AD}$ symptomatic decline.

\footnotetext{
*Correspondence: christine.landlinger@affiris.com; guenther.staffler@affiris.com

AFFiRiS AG, Karl-Farkas-Gasse 22, Vienna 1030, Austria
} 


\section{Background}

Alzheimer's disease (AD) is the most common cause of dementia in the elderly characterized by memory decline and cognitive dysfunction. Approximately 36 million individuals are currently affected worldwide (WHO 2014). The main neuropathological hallmarks in AD are extracellular amyloid $\beta$ plaques (reviewed in [1]), intracellular neurofibrillary tangles (reviewed in [2]), prominent inflammatory processes (reviewed in [3]), and as a consequence neuron loss. Originally, the deposition of amyloid $\beta$ peptides was considered to be the most crucial step that ultimately leads to $\mathrm{AD}$ dementia described as amyloid cascade hypothesis [4]. Several therapeutics that targeted amyloid $\beta$ aggregation were tested in clinical trials, however, none of them showed consistent improvements in $\mathrm{AD}$ patients (reviewed in $[5,6])$. Although amyloid aggregation is still considered to be a driving factor in the onset of $\mathrm{AD}$, it is known that amyloid depositions can occur among the elderly also without cognitive impairment $[7,8]$. In addition, it was shown in transgenic mouse models that $A \beta$ alone is not sufficient for cellular and cognitive loss [9].

Besides amyloid $\beta$ aggregation, a strong activation of inflammatory processes was observed in the brains of AD-affected individuals [10-12]. Reactive microglia cells were found throughout the cortex and hippocampus of patients with $\mathrm{AD}$ and were particularly concentrated in the areas of plaque formation [13, 14]. The interference with neuroinflammation has therefore gained considerable attention as a potential therapeutic approach in recent years $[3,15]$.

Inflammatory processes in $\mathrm{AD}$ are primarily triggered by the up-regulation of the complement system in response to misfolded and aggregated proteins or mislocalized nucleic acids and reactive microglia [10, 16, 17]. Prolonged chronic neuroinflammation is thought to reinforce neuronal cell dysfunction and cell death $[18,19]$. Notably, the pro-inflammatory complement factor C5a and its receptor have been found to be up-regulated in microglia in the immediate surroundings of cerebral amyloid plaques in different mouse models of AD [20]. It was shown that the blockage of $\mathrm{C} 5 \mathrm{aR}$ by the antagonist PMX205 lead to a therapeutic benefit in a rat model of neurodegeneration [21]. This inhibitor was also tested in $\mathrm{Tg} 2576$ and 3xTg mice, two different mouse models of $\mathrm{AD}$, and showed improved memory skills and reduced amyloid plaque formation [22]. Furthermore, it was reported that $\mathrm{C} 5$-deficient $\mathrm{DAB} / 2$ mice, which carry the human APP transgene, had significantly lower $A \beta$ levels compared to C5-sufficient C57BL/6 mice with the identical transgene [23].

In this study, we investigate the therapeutic effect of the interference with neuroinflammation by an active vaccination directed against the complement factor $\mathrm{C} 5 \mathrm{a}$ in a mouse model of AD.
For this propose, two antigenic peptides, which are able to induce a humoral immune response against a $\mathrm{C}$-terminal epitope of the murine $\mathrm{C} 5 \mathrm{a}$ molecule, were selected and subsequently tested in wild-type (wt) and $\operatorname{Tg} 2576$ mice. Both peptide vaccines were able to specifically target C5a and found to ameliorate memory deficits and neuropathology in AD-like disease.

\section{Methods}

\section{Animals}

Both sexes of $\operatorname{Tg} 2576$ mice on a 129 S6 genetic background were used (Taconic, Denmark). Tg2576 mice carry a transgene coding for the 695-amino acid isoform of the human AD amyloid precursor protein (APP) and the Swedish mutation (KM670/671NL) [24]. The mice were bred by the provider by backcrossing hemizygous male mice with $129 \mathrm{~S} 6 / \mathrm{SvEvTac}$ female mice. It is reported that memory deficits in this model start at an age of 6 months and at 9-12 months amyloid plaques in the cortex and hippocampus become apparent similar to $\mathrm{Tg} 2576$ mice on a C57BL/ $6 \times \mathrm{SJL}$ genetic background which is a more commonly used strain in the context of AD-like pathology. Mice on 129S6 background, however, are supposed to provide more genetic homogeneity and thus represent a reasonable and validated strain of $\operatorname{Tg} 2576$ mice [25]. 129S6 wt mice were used as a control (Taconic, Denmark). Mice were housed at the University of Vienna (Himberg, Austria) and kept under a 12-h light/dark cycle. Food and water was offered ad libitum.

All animal experiments were performed in accordance with the guidelines for care and use of laboratory animals of the Austrian Animal Experiments Act. The protocol was ethical approved and issued by the Lower Austrian Provincial government (permit number: LF1-TVG-22/0102011).

\section{Peptide vaccine preparation and application}

The proprietary AFFITOME ${ }^{\oplus}$ technology [26] was used to develop short immunogenic peptides (AFFITOPE's), which mimic a C-terminal epitope of murine C5a. This technology enables the design of peptides which induce an antibody response that discriminates between the two forms of C5a, C5a ARG and the metabolized C5a desARG. The peptides (AFFITOPE ${ }^{\circ}$ s) AFF1 and AFF2 were synthesized by FMOC solid phase peptide synthesis and HPLC-purified (EMC microcollections $\mathrm{GmbH}$, Germany). These peptides contain an additional Nterminal cysteine residue and were activated with the cross linker N-[g-Maleimidobutyryloxy]succinimide ester (GMBS, Pierce) according to manufacturer's protocol and covalently linked to the carrier Keyhole Limpet Hemocyanin protein (KLH, Biosyn GmbH). The KLHconjugated peptides were dissolved in $1 \times$ PBS (PAA) and absorbed to $0.2 \%$ Alhydrogel $^{\circ}$ (Brenntag Biosector, 
Denmark). Thirty micrograms of KLH-conjugated peptides were used for one dose of injection, which was applied subcutaneously in $200 \mu \mathrm{l}$. KLH vaccines without the peptide moiety were used as a control vaccine.

\section{Immunization scheme}

Non-AD 129S6 mice (wt mice) were immunized with AFF1- $(n=12)$ and AFF2- $(n=12)$ containing vaccines as well as vehicle control $(n=12)$ at the age of 11 months 3 times in a biweekly interval followed by two further immunizations in monthly intervals.

C5a-peptide vaccination in $\operatorname{Tg} 2576$ mice was performed in two studies starting at two different time points. In the first study, which was timely staggered into two parts, $\operatorname{Tg} 2576$ mice received either C5a-peptide vaccine AFF1 $(n=23)$ or AFF2 $(n=23)$ at the age of 8 months. All animals were immunized 4 times in a biweekly interval followed by three injections once a month until the age of 13 months. In the second study, the prime immunization of $\mathrm{Tg} 2576$ mice was performed at the age of 11 months using only AFF1-formulated vaccine $(n=9)$. These animals were immunized 4 times in a biweekly interval followed by the last immunization a month later. Control treated animals for study $1(n=14)$ and study $2(n=9)$ were injected with the control vaccine at the same time intervals as the study groups.

\section{ELISA}

To determine the levels of $\mathrm{C}^{\mathrm{a}} \mathrm{a}-\mathrm{AFFITOPE}^{\oplus}$ vaccine-induced antibodies, plasma and CSF samples were collected and analyzed by ELISA. Briefly, $1 \mu \mathrm{M}$ of the antigenic peptides AFF1, AFF2, or an irrelevant control peptide all coupled to BSA were coated in $0.1 \mathrm{M}$ $\mathrm{NaHCO}_{3}$ (pH 9.2-9.4) to a 96-well Nunc-MaxiSorp plate. In order to test the reactivity against the target protein, $0.5 \mu \mathrm{g} / \mathrm{ml}$ of the recombinant murine C5a ARG and C5a desARG (Hycult Biotech) were coated in $1 \times$ PBS. Free binding sites were blocked by the incubation with blocking buffer ( $1 \times$ PBS, $1 \%$ BSA) for $1 \mathrm{~h}$ at $37^{\circ} \mathrm{C}$. Plasma (1:100) and CSF (1:10), respectively, were added, serially diluted $1: 2$, and incubated for $1 \mathrm{~h}$ at $37^{\circ} \mathrm{C}$. For the detection, biotinylated anti-mu $\operatorname{IgG}(\mathrm{H}+\mathrm{L})$ (Southern Biotech.; 1:2000) in 1× PBS/0.1 \% BSA/0.1\% Tween 20 was applied and incubated for $1 \mathrm{~h}$ at $37^{\circ} \mathrm{C}$. As a next step, horseradish peroxidase coupled to streptavidin (Roche) was added $\left(30 \mathrm{~min}, 37^{\circ} \mathrm{C}\right)$ followed by the addition of the substrate 2,2'-Azinobis [3-ethylbenzothiazoline-6-sulfonic acid]-diammonium salt (ABTS) (BioChemica, AppliChem) (30 min, RT). The optical density (OD) at $405 \mathrm{~nm}$ was measured with a microwell plate reader (Sunrise, Tecan, Switzerland) and the titers were defined as the dilution factor referring to $50 \%$ of the maximal optical density $\left(\mathrm{OD}_{\max } / 2\right)$. The mean titers \pm SEM of all animals per group are presented.

\section{Western blot analysis}

Two-hundred nanograms of recombinant mouse C5a ARG and C5a desARG (Hycult Biotech) were loaded on a Bio Rad 4-20 \% Criterion ${ }^{\mathrm{Tm}} \mathrm{TGX}^{\mathrm{m}}$ gel under nonreducing conditions. For the detection, immune plasma (1:50) of AFF1, AFF2, or control immunized Tg2576 mice as well as plasma obtained from untreated wt mice were used. Rabbit anti-mouse C5a antibody (Abbiotech, 1:200) was used as a control antibody. As a secondary antibody, a goat anti-mouse HRP IgG (1:20.000) for the plasma samples and a rabbit anti-goat HRP IgG (1:20.000) for the control antibody were applied. The Precision Plus Protein ${ }^{\text {Tx }}$ Dual Color Standards (Bio-Rad) was used as a marker.

\section{C5a sandwich ELISA}

Changes in the C5a levels in the plasma of individual Tg2576 mice before (at the age of 8 months) and after the last immunization (at the age of 15 months) with AFF1-, AFF2-, and vehicle-containing vaccines was determined by a C5a sandwich ELISA. Briefly, 96-well Nunc-MaxiSorp plates were coated with the monoclonal rat anti-mouse C5a antibody (R\&D, MAB21501). Plates were blocked with $1 \times$ PBS/1 \% BSA. Subsequently, plasma obtained 1 day before the first immunization and 8-9 weeks after the last immunization were applied at a starting dilution of 1:10 and serially diluted 1:2 in $1 \times \mathrm{PBS} /$ $0.1 \% \mathrm{BSA} / 0.1 \%$ Tween 20 and incubated for $1 \mathrm{~h}$ at $37{ }^{\circ} \mathrm{C}$. For the detection of bound $\mathrm{C} 5 \mathrm{a}$, the biotinylated polyclonal goat anti-mouse complement component C5a antibody (R\&D, BAF2150) was applied for $1 \mathrm{~h}$ at $37{ }^{\circ} \mathrm{C}$. Horseradish peroxidase coupled to streptavidin (Roche) was added $\left(30 \mathrm{~min}, 37^{\circ} \mathrm{C}\right)$ followed by the addition of the substrate ABTS (BioChemica, AppliChem) (30 min, RT). The OD at $405 \mathrm{~nm}$ was determined by a microwell plate reader (Sunrise, Tecan, Switzerland). The relative changes in OD values at a dilution of 1:40 of plasma samples obtained before $(=100 \%)$ and after the last immunization of each individual mouse were evaluated. Plasma obtained from untreated wt mice was used as a control. The group means \pm SEM of $n$ animals are presented.

\section{Contextual memory test}

Contextual learning and memory of C5a-peptide and control-immunized Tg2576, as well as 129 S6 wt mice, were determined by a contextual fear conditioning test at the age of 15 months. A contextual fear conditioning apparatus Ugo Basile 1-cage fear conditioning set-up (UGO BASILE S.r.l. Biological Research Apparatus Via Guido Borghi 43; I-21025 Comerio, Varese; Italy) was used. Fear conditioning training was performed 1 day before the test. Each mouse was placed in the conditioning chamber and exposed to a program allowing the mouse to habituate for $2 \mathrm{~min}$ to the chamber, followed 
by three foot shocks $(0.8 \mathrm{~mA})$ in 2-min intervals and a 30 -s rest. The movement of the mouse was monitored by a camera (Firewire camera Fire-I BBW 1.3 (Unibrain)) and analyzed by the computerized tracking software ANY-maze (ANY-maze Video Tracking System 4.73-4.91, Stoelting). To assess contextual learning and memory, $24 \mathrm{~h}$ after the initial training, the mouse was again placed in the conditioning chamber and the ANYmaze video tracking software was started. This time, the animal received no electric shocks. Each mouse was monitored in the chamber for $5 \mathrm{~min}$ for immobile episodes (i.e., time freezing) representing their ability to recall the foot shocks they received the previous day.

\section{Modified SHIRPA test}

$129 S 6$ wt mice were immunized with AFF1-, AFF2-, or vehicle-containing vaccines starting at the age of 11 months and at the age of 15 months, comprehensive analyses of general health, muscle function, and sensory function were performed by a modified SHIRPA test as previously described at the European Mouse Phenotyping Resource Standardized Screens (EMPReSS) database (http://empress.har.mrc.ac.uk/). Briefly, eye closure (score $0=$ no, score $1=$ yes $/$ normal), missing whiskers (score $0=$ no/normal, score $1=$ yes), tail curl (score $0=$ abnormal, score $1=$ normal), respiratory function (score $0=$ gasping/arrhythmic, score $1=$ normal), and body weight were evaluated for general health parameters. For the evaluation of the sensory abilities, visual forepaw reach (score $0=$ no, score 1 = weak, score 2 =clear placing reaction/normal), auditory startle (score $0=$ no, score $1=$ present $/$ normal), and ear and whisker twitch (score $0=$ absent, score $1=$ present $/$ normal) were assessed. The muscle functions were evaluated based on pelvic elevation (score $0=$ low, score $1=$ normal), truck curl (score $0=$ absent, score $1=$ present $/$ normal), righting reflex (score $0=$ absent $/$ impaired, score $1=$ present $/$ normal), clasping (score $0=$ no, score $1=1$ paw, score $2=2$ paws), forelimb grip (score $0=$ no, score $1=$ weak, score $2=$ normal), and grasping reflex (score $0=$ no/all 4 paws impaired, score $1=$ fore and hind limbs impaired, score $2=$ all 4 paws normal).

\section{Immunohistochemistry and image analysis}

The mouse brain was isolated and without perfusion, the left hemi-brain was fixed $\mathrm{o} / \mathrm{n}$ in $4 \%$ paraformaldehyde (PFA, Merck) at $4{ }^{\circ} \mathrm{C}$. The tissue was embedded in paraffin, and coronal sections $(7 \mu \mathrm{m})$ containing the frontal, middle, and distal hippocampal region (bregma distance $-1.60,-2.10$, and $-2.60 \mathrm{~mm}$ ) were used for immunohistochemical staining. After rehydration and treatment with antigen retrieval $\mathrm{pH}=9.0$ (Dako), the tissues were blocked with $4 \%$ normal goat or rabbit serum, respectively (Sigma). Serial sections were incubated with the corresponding primary antibody or control IgG. A $\beta$ deposits were detected by an in-house generated mouse $3 \mathrm{~A} 5$ monoclonal antibody $(\mathrm{mAB})$ that specifically binds to the $\mathrm{N}$-terminal part of $\mathrm{A} \beta$ [27]. Activated CD45 high microglia cells were visualized by the goat anti-mouse CD45 antibody (AF114) obtained from R\&D systems. Fluorescent anti-mouse $\operatorname{IgG}(\mathrm{H}+\mathrm{L})$ and Fluorescent anti-goat $\operatorname{IgG}(\mathrm{H}+\mathrm{L})$ (Vector Laboratories) were used for the detection of 3A5 and CD45 antibody, respectively. The cover slides were mounted with Vectashield ${ }^{\circ}$ Hard Set ${ }^{\text {tax }}$ Mounting Medium with 4',6-diamidino-2phenylindole (DAPI) (Vector Laboratories), dried for 2 days in the dark. Slides were then scanned by the Mirax Scan 150 automated whole slide scanner (Karl Zeiss AG). The relative amyloid plaque area (3A5 staining) within the total tissue area of coronal cross sections of the brain including the cortex, hippocampus, and the brain stem was analyzed by a semi-automated area recognition program (eDefiniens Architect XD; www.definiens.com). CD $45^{\text {high }}$ cells in the hippocampal region were counted manually. Immunostaining and analysis of each marker was performed from 6-12 sections of each individual mouse brain derived from 3 defined bregma distances all including the hippocampal region. The mean value of all sections per mouse was calculated and the means per group \pm SEM of $n$ animals are presented.

\section{Statistical analysis}

All values were evaluated for homoscedasticity and normality assumption using both Kruskal-Wallis and Shapiro-Wilk normality tests. To determine statistical significance of more than two groups, values were compared using one-way ANOVA followed by the Tukey's multiple comparison tests (parametric test) or one-way ANOVA with the Dunn's test (non-parametric test). For the comparison of two groups, the unpaired two-tailed Student's $t$-test was used, followed by the MannWhitney correction for non-parametric data as indicated in the respective figure legend.

The $p$ values $\leq 0.05$ were considered significant and are expressed as " $p<0.05$ and $" p<0.01$.

\section{Results}

Immunogenicity and safety of anti-C5a-peptide vaccines in wt mice

Peptides (AFFITOPE ${ }^{\oplus}$ ) mimicking the C-terminal neoepitope of murine C5a were designed, formulated, and tested in 129S6 wt mice for their immunogenicity and ability to induce antibodies against the endogenous target protein C5a (Fig. 1). C5a is present in two different forms, the highly active C5a ARG which becomes rapidly metabolized by a carboxypeptidase to the less active though more stable C5a molecule without the Cterminal arginine, C5a desARG. As the relevance of the 


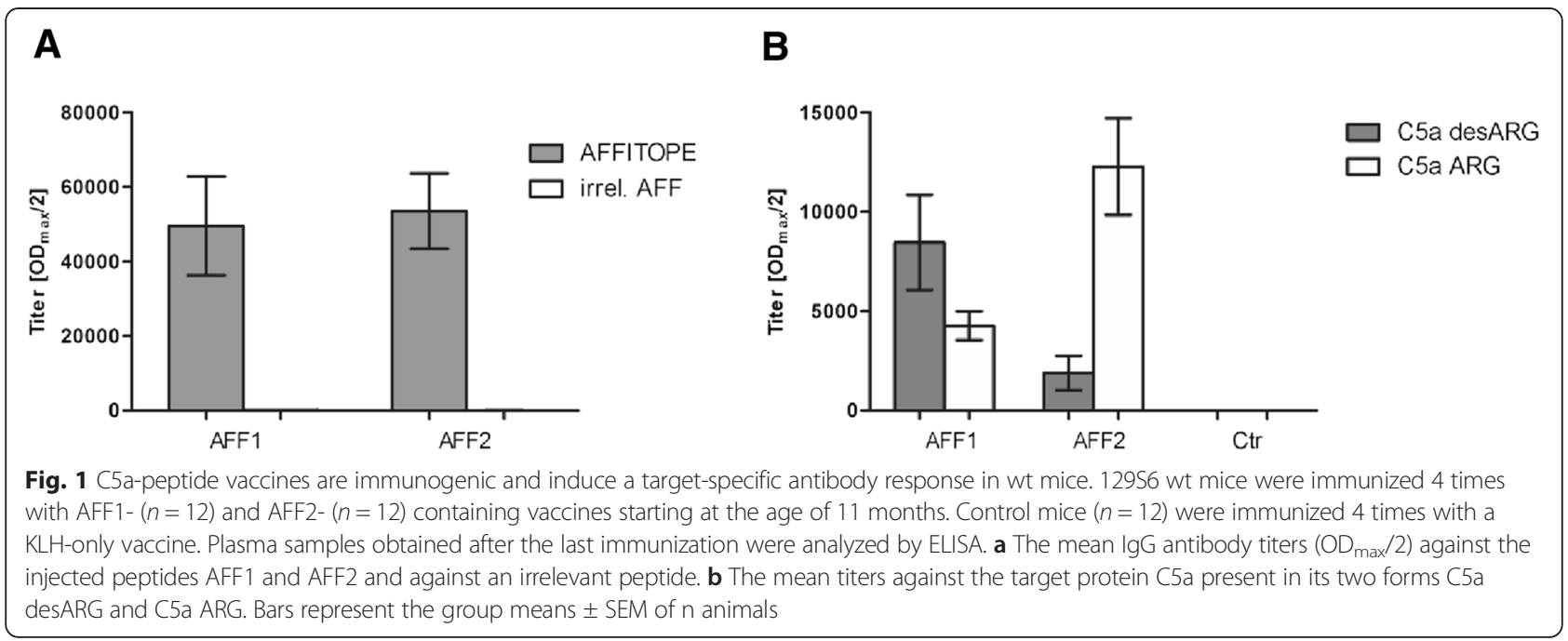

two different forms of $\mathrm{C} 5 \mathrm{a}$ in neuro-inflammatory disease is still unknown, different C5a-targeting peptides (AFFITOPE ${ }^{\oplus}$ s), AFF1 and AFF2, have been selected for in vivo testing. Both AFF1- and AFF2-containing vaccines elicited similarly high titers of approximately $1 /$ 50.000 against their antigenic peptide moiety (Fig. 1a). No cross-reactivity against an unrelated irrelevant peptide was observed (Fig. 1a). However, their reactivity against the different forms of the target protein differed. AFF1-containing vaccine mounted higher antibody titers against C5a desARG, whereas AFF2-containing vaccine primarily induced a strong immune response against the more active molecule, C5a ARG (Fig. 1b). As expected, control immunized mice did not show any immune response against C5a ARG and C5a desARG (Fig. 1b).

Before testing the C5a-peptide vaccines for their efficacy in a mouse model of $\mathrm{AD}$, we investigated whether these vaccines had any effect on the contextual learning and memory in $129 \mathrm{~S} 6$ wt mice by using the contextual fear conditioning test. After four immunizations, no differences between the control and the C5a-AFFITOPE ${ }^{\circledR}$ immunized mice were observed all showing around $60 \%$ time freezing within a 2-min period of analysis (Fig. 2a). Furthermore, potential side effects of the vaccines were evaluated by a modified SHIRPA test including general health, muscle, and sensory functions. C5a-peptide and vehicle-immunized $129 S 6$ wt mice were all healthy (Fig. 2b), had comparable body weight (Fig. 2c), and no abnormalities in sensory and motor functions were observed (Fig. 2d, e). In addition, different safety parameters were elucidated by in silico analyses. The absence of target-specific $\mathrm{T}$ cell response and cross-reactivity of vaccine-induced antibodies to other endogenous proteins are a prerequisite for an immunotherapy against self-proteins in order to avoid the risk of autoimmunity. In silico analysis by online available $\mathrm{T}$ cell epitope prediction algorithms (e.g., http://www.syfpeithi.de or http://www.iedb.org/counts.php) did not predict any relevant $\mathrm{T}$ cell epitope for the peptides AFF1 and AFF2. Potential cross-reactivity of the AFF1- and AFF2-induced antibodies to other proteins was evaluated by BLAST searches against the murine proteome. AFF1 did not show any relevant homology to other murine proteins. For AFF2, a homology of 6 amino acids to FYN binding protein was found, however, based on its intracellular location, it is not anticipated to be accessible for antibody binding.

\section{Immunogenicity in Tg2576 mice}

Human APP transgenic Tg2576 mice on a 129 S6 genetic background were used as a model of AD-like disease. In a first study, starting at the age of 8 months, Tg2576 mice were either immunized with AFF1- or AFF2-formulated anti-C5a vaccines. Two weeks after the second immunization (W4), titers against the immunizing peptides AFF1 and AFF2 approached approximately $1 / 20.000$ and $1 / 45.000$, respectively, and remained at this level until week 28 (W28) corresponding to 15 months of age (Fig. 3a). Compared to the results obtained from immunized wt mice, AFF2containing vaccines induced similar high titers against the antigenic peptide AFF2, whereas AFF1-containing vaccines elicited a clearly lower titer against the peptide moiety (Figs. 1a and 3a). ELISA for the proteins C5a desARG and C5a ARG revealed that AFF1-containing vaccine mounted higher antibody titers against $\mathrm{C} 5 \mathrm{a}$ desARG whereas AFF2-containing vaccine showed a much higher immune response against C5a ARG (Fig. 3b), similar to those results obtained from AFF1 and AFF2 immunized wt mice (Fig. 1b). As expected, control immunized mice did not show any immune response against the C5a proteins (Fig. 3b). Western blot analyses using recombinant C5a ARG and C5a desARG confirmed this reactivity pattern of AFF1- and AFF2- 


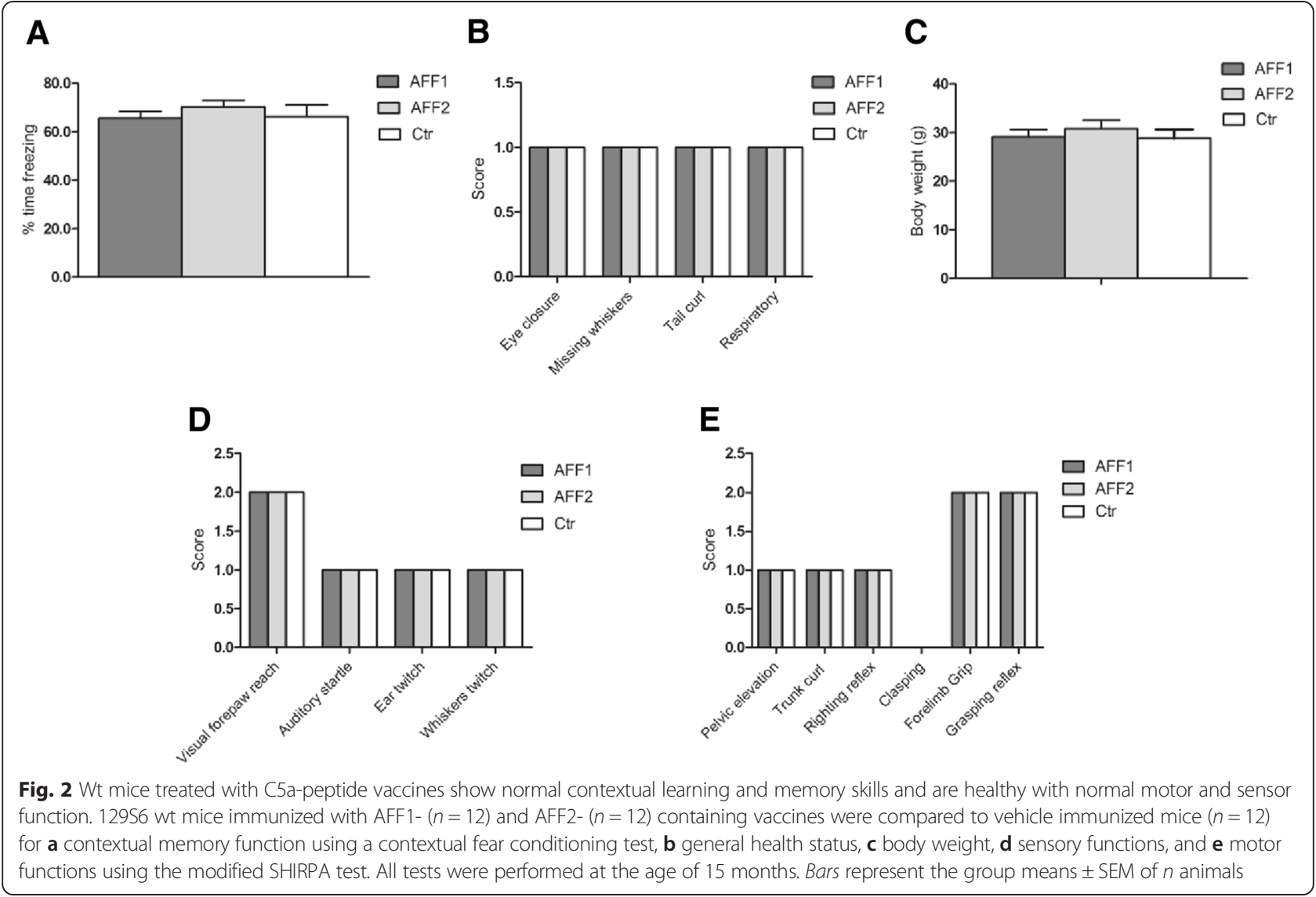

induced antibodies. Again, AFF1-elicited antibodies showed a better recognition for C5a desARG, whereas AFF2-induced immune plasma revealed a stronger band for C5a ARG. Control immunized mice as well as plasma obtained from untreated wt littermates at the age of 15 months did not show any signal toward both forms of C5a (Fig. 3c).

In order to assess whether AFF1- and AFF2-induced antibodies reach their target in the brain, cerebrospinal fluid (CSF) was obtained and analyzed for the presence of AFFITOPE ${ }^{\ominus}$-specific antibodies by ELISA. Antibodies could be detected in the CSF ranging from 0.2 to $0.4 \%$ of their corresponding titers in plasma (Fig. 3d).

\section{C5a-peptide vaccines deplete $\mathrm{C} 5 \mathrm{a}$ from the circulation}

The plasma concentration of $\mathrm{C} 5 \mathrm{a}$ was used as a surrogate for antibody binding efficacy to $\mathrm{C} 5 \mathrm{a}$ of vaccine-induced antibodies. The changes of the total C5a levels in the plasma obtained before (refers to $100 \%$ ) and after the last immunization of AFF1, AFF2, and control immunized Tg2576 mice were assessed. The levels of C5a were significantly reduced to 68 and $72 \%$ in AFF1- and AFF2-treated mice, respectively, whereas control immunized mice showed an increase of C5a up to $124 \%$ (Fig. 4), indicating an in vivo target engagement of $\mathrm{AFFITOPE}^{\oplus}$-induced antibodies. As an additional control, plasma from untreated wt mice was analyzed showing a constant level of C5a in the plasma of 8-vs. 15-month-old mice (Fig. 4).

Early stage immunization improves contextual memory and reduces the number of activated microglia and amyloid plaque load in Tg2576 mice

In a first set of experiments, anti-C5a immunization of Tg2576 mice by AFF1- and AFF2-containing vaccines was started at the age of 8 months, where first memory deficits are reported to become apparent in this model, but amyloid plaques in the brain are not yet present. A contextual fear conditioning test was performed at the age of 15 months in order to investigate the impact of C5atargeting vaccines on the progression of $\mathrm{AD}$-like cognitive decline. The time freezing was used to measure mice's ability to recall the shocks they received on the previous day. Both AFF1- and AFF2-vaccinated mice showed significantly increased memory retention with 32 and $27 \%$ time freezing, respectively, whereas control-treated mice spent only $10 \%$ time freezing indicating an almost complete loss of contextual learning and memory (Fig. 5). However, vaccination was not able to restore the contextual learning and memory conditions which were found in untreated wt littermates (47\% time freezing) (Fig. 5). 


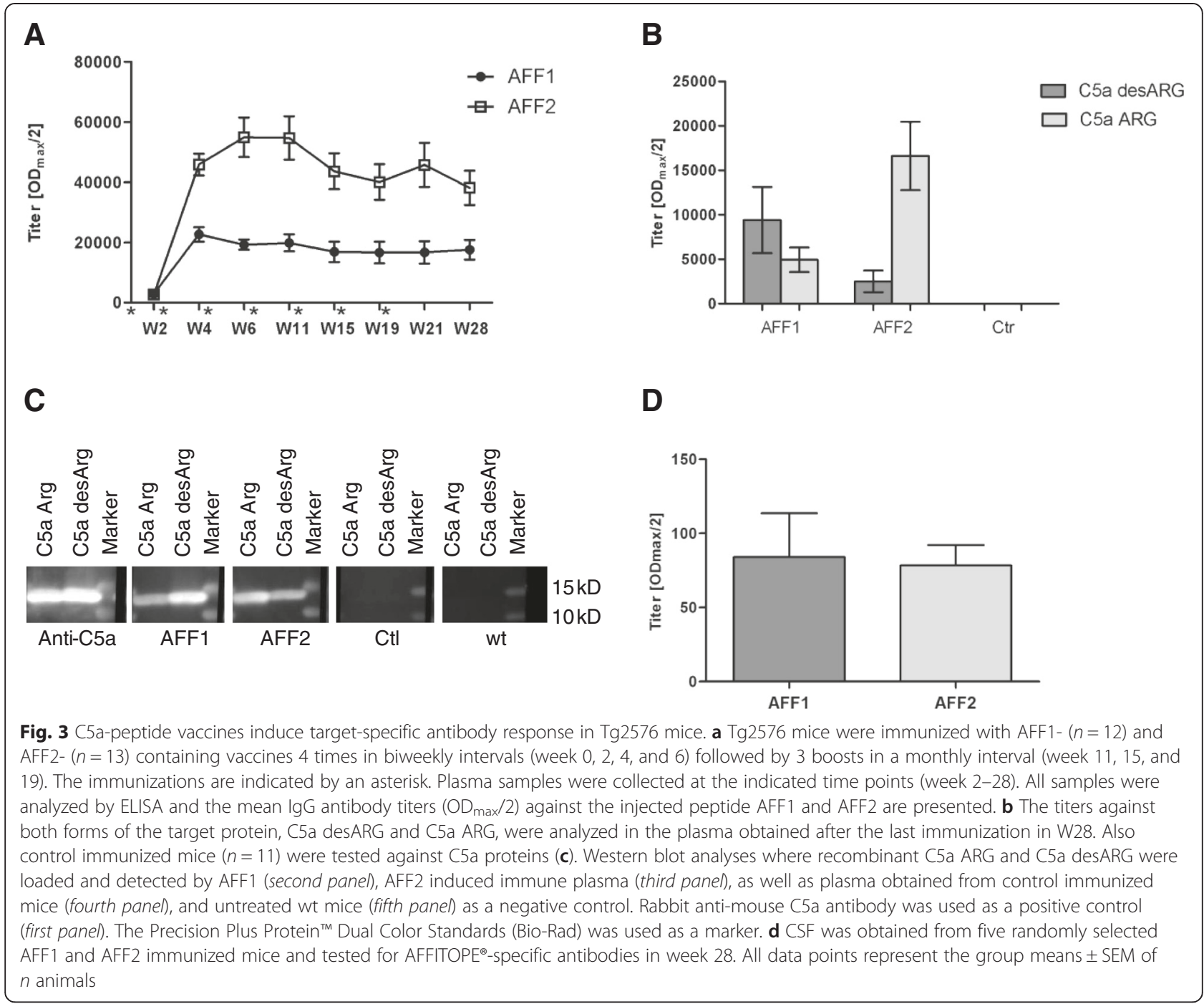

Non-AD wt littermates have not been included in this study. To evaluate that the memory improvements in AFF1- and AFF2-vaccinated Tg2576 mice can be attributed to the neutralization of excessive C5a which was provoked by the APP transgene, an independent control experiment was performed. Wt mice were immunized 4 times with AFF1 and AFF2 vaccines and tested for memory retention by a contextual fear conditioning test. No differences between the control and the C5a-AFFITOPE ${ }^{\circ}$ immunized mice were found as already shown in Fig. 2a.

In order to investigate the impact of anti-C5a vaccination on microgliosis in the hippocampus, immunohistochemical analysis of CD $45^{\text {high }}$ cells in the brain of AFF1-, AFF2-, and control-treated Tg2576 mice at the age of 15 months was performed (Fig 6a). Compared to control, both AFF1- and AFF2-formulated vaccines significantly reduced the number of CD45positive $\left(\mathrm{CD} 45^{\text {high }}\right)$ microglia in the hippocampus (Fig. 6b).
We further analyzed whether anti-C5a vaccination also had an influence on the cerebral $A \beta$ pathology, a major hallmark of $A D$ progression. The in-house generated $A \beta$ specific mAB 3A5 [27] was used to detect $A \beta$ depositions in the brain of 15-month-old mice treated with AFF1, AFF2, or the control vaccine (Fig. 6c). Both, AFF1- and AFF2-treated mice, revealed a statistically significant reduction of cerebral amyloid burden exhibiting $0.39 \%$ in AFF1 $(p<0.01)$ and $0.42 \%(p<0.05)$ in AFF2 amyloid plaque area of the total coronal brain section, compared to $0.55 \%$ in control immunized mice (Fig. $6 \mathrm{~d}$ ).

Late-stage vaccination improves memory function and reduces the number of activated microglia but has no influence on amyloid burden in the brain

In order to determine if the beneficial effects of our antiC5a vaccines which were observed upon early stage treatment could also be seen in a more progressed stage of Alzheimer-like disease, AFFITOPE ${ }^{\ominus}$ immunization was 


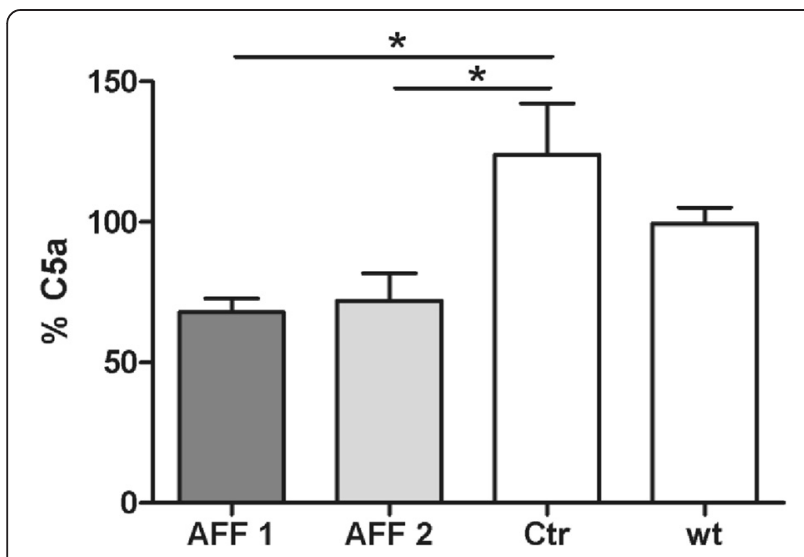

Fig. 4 Depletion of C5a from the circulation through C5a-peptide vaccination. The changes of C 5 a concentration in the plasma of $\mathrm{Tg} 2576$ mice before (at the age of 8 months) and after the treatment (at the age of 15 months) with AFF1- $(n=12)$, AFF2- $(n=13)$, or vehicle- $(n=11)$ containing vaccines were determined by sandwich ELISA. The level of C5a in the plasma obtained before the immunization start at the age of 8 months refers to $100 \%$. The C5a level in the plasma of untreated wt mice $(n=6)$ at the age of 8 months vs. 15 months is also shown. Bars represent the group means \pm SEM of $n$ animals. The one-way ANOVA test followed by a Tukey's multiple comparison Test (parametric test) was applied to determine the $p$ values $\left({ }^{*} p<0.05\right.$ and $\left.{ }^{* *} p<0.01\right)$

started at the age of 11 months, where memory deficits and cerebral amyloid depositions are already clearly pronounced. Mice were immunized with AFF1-containing vaccines 4 times in a biweekly interval followed by the final immunization 1 month later. A contextual fear conditioning test was performed at the age of 15 months in order to assess the influence of the anti-C5a vaccination on memory impairment. Compared to the control vaccine, AFF1vaccinated mice showed a tendency of better contextual learning and memory skills indicated by $18 \%$ vs. $7 \%$ time freezing (Fig. 7a, $p=0.182$ ). Untreated wt littermates showed $51 \%$ time freezing similar to the result obtained in Fig. 5. Again, wt littermates treated with AFF1 vaccine have not been included in this study. However, an independently performed control experiment showed that the memory retention of control and AFF1-immunized wt mice was similar (see Fig. 2a).

When evaluating the number of $\mathrm{CD} 45^{\text {high }}$ microglia cells in the hippocampus, a significant reduction in AFF1 compared to control-treated Tg2576 mice was found (Fig. 7b).

In contrast to $\mathrm{Tg} 2576$ mice immunized at an early stage of the disease (Fig. 6d), cerebral amyloid burden was not reduced upon late-stage treatment with antiC5a vaccine (Fig. 7c).

\section{Conclusion}

Active vaccination against the pro-inflammatory molecule C5a represents a novel and well-tolerated therapeutic approach to interfere with neuroinflammation in a mouse model of AD. Early- as well as late-stage treatment with C5a-peptide vaccines reduced microgliosis and improved cognitive function. Amyloid plaque burden, however, was only affected in an early onset of vaccination, thus we suppose that C5a-mediated neuroinflammation more than amyloid $\beta$ aggregation is a driving factor for memory decline in this model of AD.

\section{Discussion}

The present study shows that active immunization with C5a-peptide vaccines AFF1 and AFF2 elicits antibodies that effectively bind $\mathrm{C} 5 \mathrm{a}$ and reduce the number of activated microglia in the hippocampus, accompanied by memory improvements in a mouse model of AD. Moreover, cerebral amyloid plaque load was decreased upon an early-stage treatment with C5a-peptide vaccines.

An early characteristic of $\mathrm{AD}$ is the generation of amyloid proteins by the increased proteolytic cleavage of amyloid precursor proteins (APP) which start to accumulate and aggregate especially in the hippocampal and cortical region of the brain. Neuroinflammation also plays a critical role in the pathogenesis of $\mathrm{AD}$, although the mechanisms through which amyloid aggregation and deposition provoke inflammation are not fully understood. Microglia attraction and activation by amyloid plaque formation may play a detrimental role (reviewed in $[10,12])$. Microglia can be activated by direct interaction with misfolded or aberrant endogenous molecule patterns via pattern recognition receptors (PRRs) including scavenger receptor (SR-AI/II), CD36, RAGE, FC

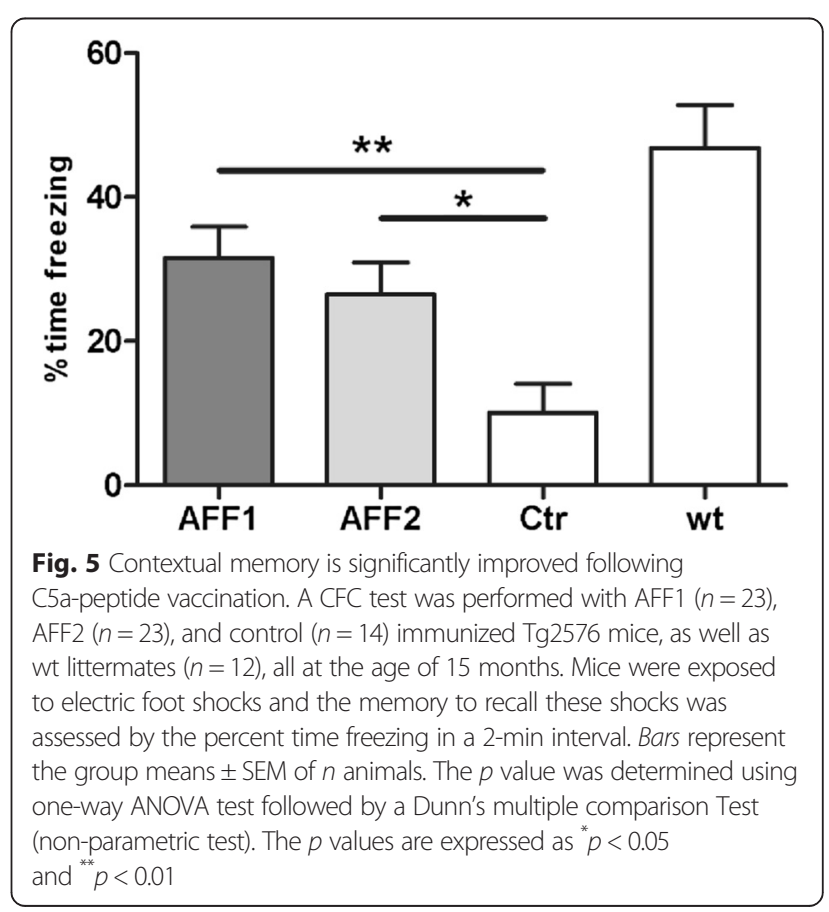




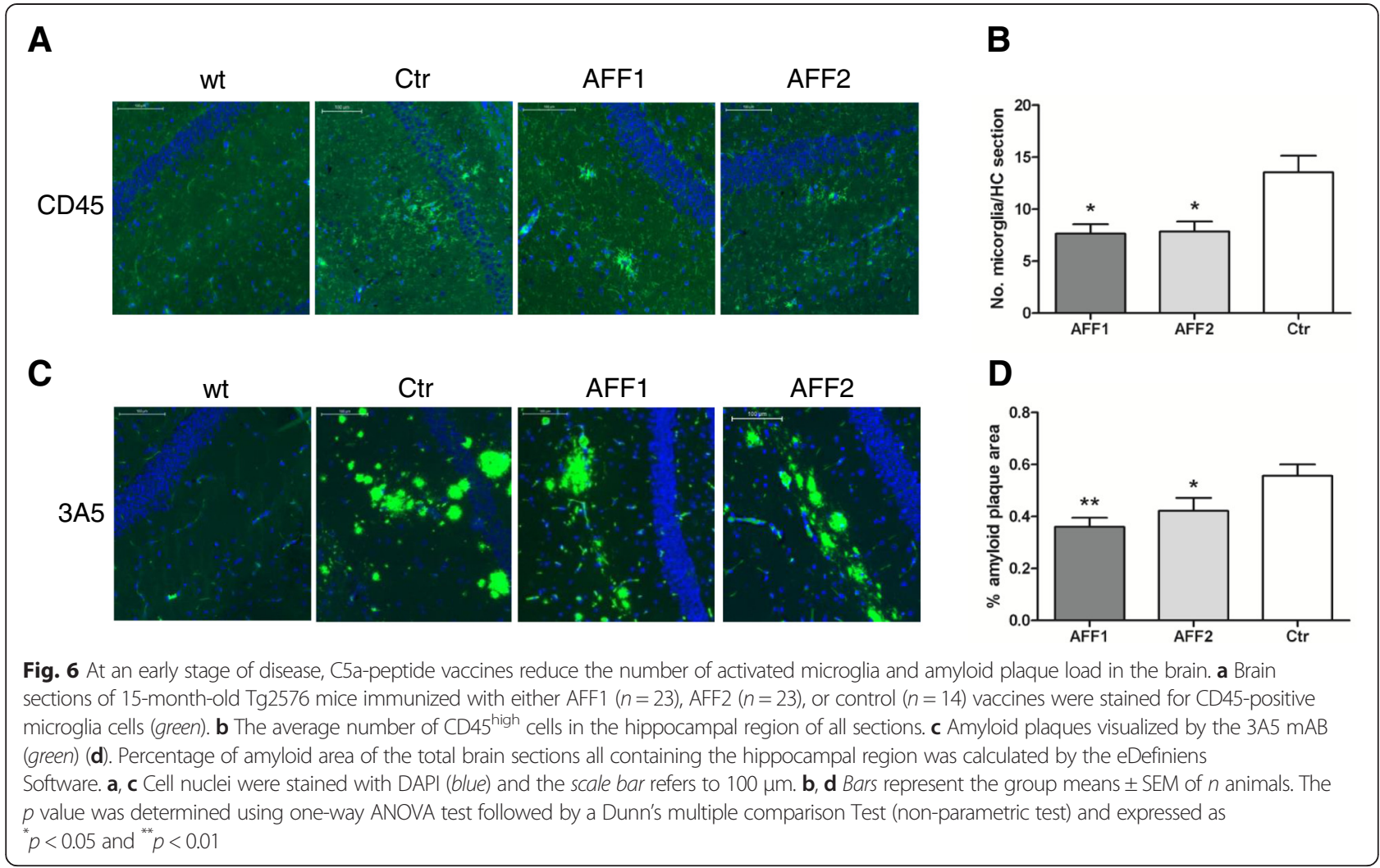

receptor, and toll-like receptors (TLRs) [28, 29]. Another important mechanism of microglia recruitment and activation is complement activation in response to $A \beta$ deposition $[30,31]$ which leads to the formation of the pro-inflammatory molecule $\mathrm{C} 5 \mathrm{a}$. C5aR was shown to be up-regulated in microglia in the immediate surroundings of plaques in the brain of different transgenic mouse models of AD [20].

Activation of microglia by $A \beta$ and complement is supposed to promote the excessive release of proinflammatory cytokines [32], chemokines [33, 34], and further complement components $[35,36]$, as well as the release of reactive oxygen and nitrogen species [37, 38], altogether leading to dysfunction and loss of synapse signaling [39]. Pro-inflammatory mediators provoke a number of stress conditions which, in turn, can enhance APP production and processing to amyloid peptides (A $\beta$ 1-42) [40-45]. Thus, chronic and selfsustaining inflammatory interactions between the complement system, activated microglia, stressed neurons, and $A \beta$ plaques occur, which ultimately lead to neuronal cell death and cognitive decline in $\mathrm{AD}$ patients. Our intention was to target the pro-inflammatory complement activation product $\mathrm{C} 5 \mathrm{a}$ in order to interfere with enhanced microglia activation and sustained neuroinflammation in AD (Fig. 8).
There are several publications that describe a physiological role for the anaphylatoxins $\mathrm{C} 3 \mathrm{a}$ and $\mathrm{C} 5 \mathrm{a}$ within the adult murine CNS, specifically an involvement in cell survival and neurogenesis ([46] and reviewed in [47-49]). Neuroprotective effects of C3a and C5a have been reported against glutamate-mediated neuronal excitotoxicity via MAPK-dependent inhibition of caspase-3 [50-52] and increased glial expression of the glutamate transporter GLT-1 [53]. In addition, administration of C5a in vivo has been shown to protect against kainic acid-induced neuronal apoptosis [52]. However, activation of complement and the release of C3a and C5a to an inappropriate extent has been proposed to promote tissue injury.

In the pathogenesis of $\mathrm{AD}$, the complement factors C1q [54] and C3 [55] have been reported to promote phagocytosis and clearance of fibrillar $A \beta$ and thus hinder pathologic progression in AD. The complement component $\mathrm{C} 5 \mathrm{a}$, however, is supposed to play a detrimental role in neurodegenerative diseases by persistent microglia activation resulting in excessive release of microglial inflammatory mediators, which enhance $\mathrm{A} \beta$ deposition and neuroinflammation [40, 42, 43]. It was shown that the blockage of $\mathrm{C} 5 \mathrm{aR}$ by the antagonist PMX205 lead to a therapeutic benefit in different models of neurodegeneration [21, 22], which strengthens our hypothesis that interference with $\mathrm{C} 5 \mathrm{a}$ by vaccination 


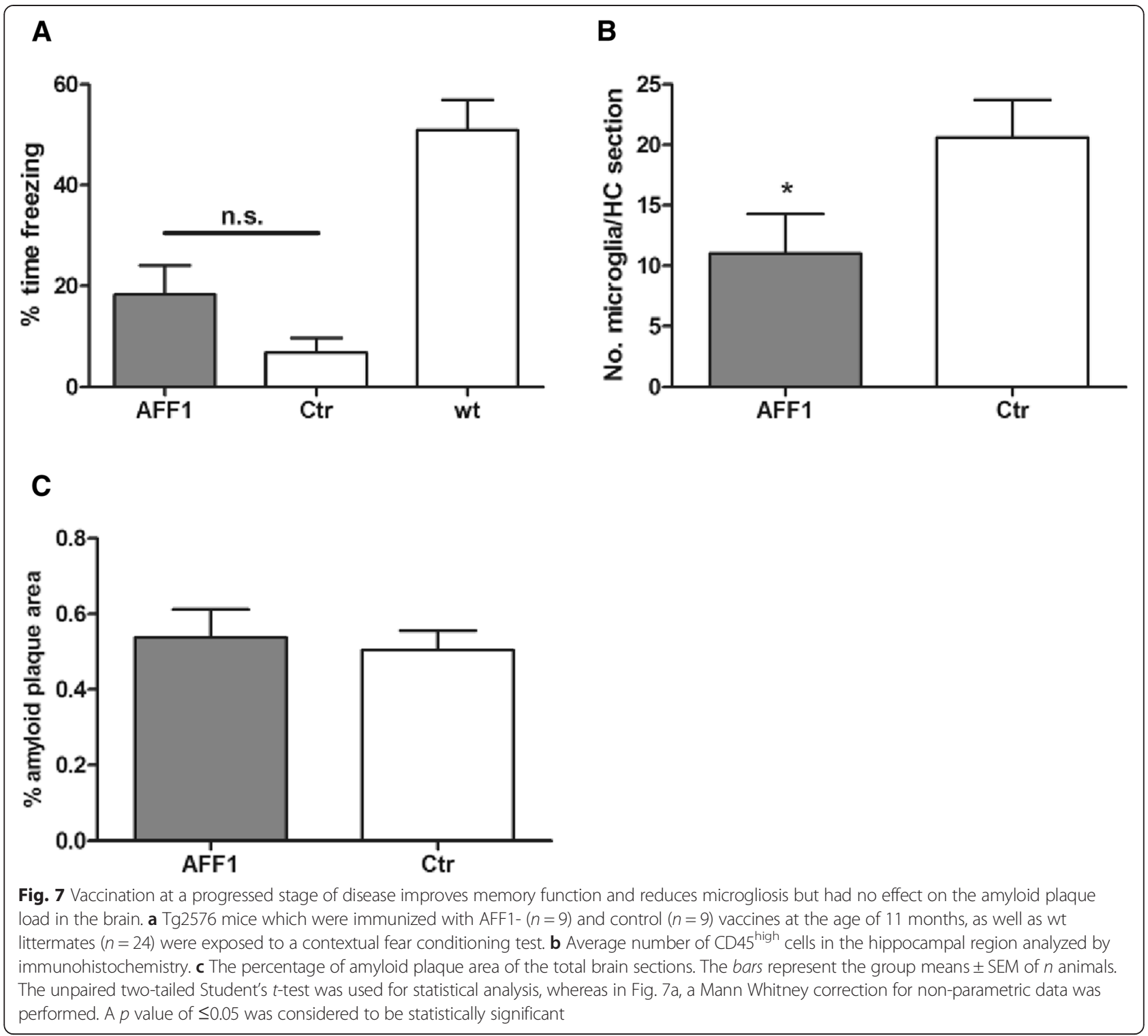

ameliorates AD pathology. The antigenic peptides AFF1 and AFF2, when coupled to the carrier protein KLH and formulated with Alhydrogel ${ }^{\circledR}$, were able to induce a strong and prolonged humoral immune response against the target protein $\mathrm{C} 5 \mathrm{a}$ in mice. Upon immunization, a reduction of total C5a in the plasma was found which indicated an effective in vivo target engagement. AFF1 and AFF2 were selected for in vivo studies, because these two peptides possess different immunogenic features. AFF1-induced antibodies react against both forms of $\mathrm{C} 5 \mathrm{a}$, the highly active C5a ARG but to a higher extent against the metabolized, less active, and more stable C5a desARG (Figs. 1b and $3 \mathrm{~b}$ ), whereas immune plasma elicited by AFF2 vaccines especially showed high titers against C5a ARG (Figs. $1 \mathrm{~b}$ and $3 \mathrm{~b}$ ). To date, the distinct function of the two forms of the anaphylatoxin $\mathrm{C} 5 \mathrm{a}$ and their contribution to chronic inflammatory diseases, such as AD, are not understood. AFF1 compared to AFF2 vaccine was found to be slightly more efficient in Tg2576 mice in terms of contextual memory retention (Fig. 5) raising the possibility that C5a desARG more than C5a ARG contributes to neuroinflammation in AD.

Most of the vaccine-induced antibodies were present in the circulation, however, a lower proportion (0.2-0.4\%) can also be detected in the CSF which let us assume that vaccine-induced anti-C5a antibodies directly reach their target in the brain. Immunohistochemistry, ELISA, and Western blot analyses were performed in order to show local anti-C5a antibody effects, but unfortunately the sensitivity of all these methods was not sufficient to detect C5a 


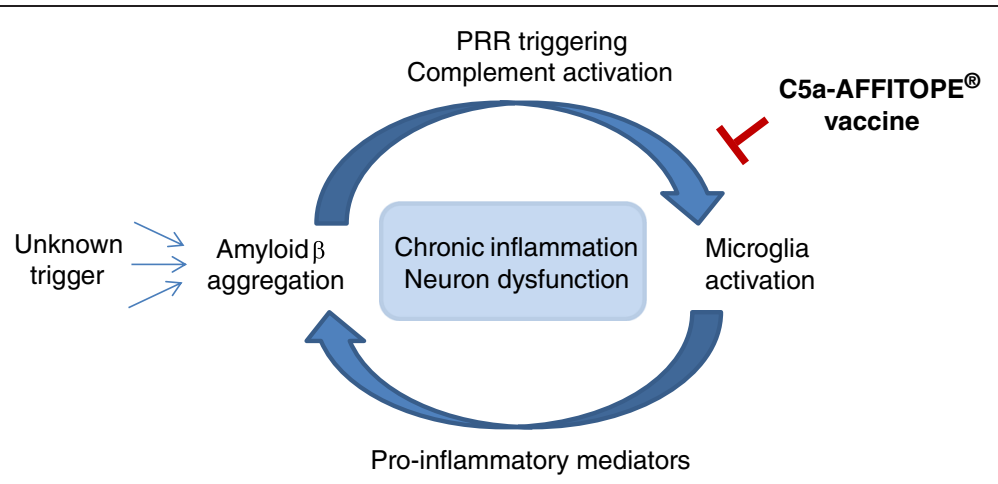

Fig. 8 Model of C5a-peptide vaccines interference with chronic, self-sustaining inflammatory processes in AD. APP processing to amyloid peptides (A $\beta$ 1-42) is influenced by an unknown trigger. $A \beta$ peptides start to aggregate in the brain and microglia become activated either by a direct interaction with misfolded $A \beta$ molecules via pattern recognition receptors (PRR) or by complement activation in the response to A $\beta$ depositions leading to the formation of the pro-inflammatory molecule C5a. We propose that C5a-AFFITOPE ${ }^{\circledR}$ vaccines interfere with the pro-inflammatory molecule C5a thereby hindering enhanced microglia activation which leads to excessive release of pro-inflammatory mediators. These pro-inflammatory mediators provoke stress conditions, which in turn reinforce APP production and processing to amyloid peptides (Aß 1-42). We believe that C5a-AFFITOPE ${ }^{\circledast}$ vaccines do have the capacity to interfere with chronic and self-sustaining inflammatory interactions between activated microglia, stressed neurons, and $A \beta$ plaques which ultimately lead to neuronal cell death and cognitive decline in $\mathrm{AD}$ patients

in the brain. However, besides local anti-C5a antibody effects, the clearance of C5a from the periphery, which we were able to show in Fig. 4, may play a crucial role in the treatment of neurodegenerative diseases, since a secondary systemic inflammatory stimulus is hypothesized to affect exaggerated response of microglia which possibly contributes to disease progression (reviewed in $[56,57]$ ).

We found that both early (at the age of 8 months) and late (at the age of 11 months) onset of anti-C5a immunotherapy reduced the number of activated microglia in the hippocampus (Figs. $6 \mathrm{~b}$ and 7b) and improved contextual learning and memory in 15-monthold Tg2576 compared to control-treated mice (Figs. 5 and $7 \mathrm{a}$ ) indicating that neuroinflammation is directly involved in memory decline and C5a may be a crucial factor that drives this inflammation. To be sure that amyloid is the main factor that provokes complement activation in Tg2576 mice and thus memory decline, an additional group of wt littermate mice immunized with anti-C5a vaccines should have been included in the above presented experiments. Since these data are not available, we cannot exclude that a secondary inflammatory stimulus may contribute to the outcome or progression of AD-like disease in these animals. However, the effect of anti-C5a immunization on non-transgenic mice was tested in an independently performed control experiment which showed that C5a-AFFITOPE ${ }^{\bullet}$ immunization did not influence the cognitive behavior (Fig. 2a).

Besides the contextual fear conditioning test, also the classical Morris water maze test, another hippocampal dependent complex learning tasks, was performed. Similar results were obtained (data not shown), although a contextual fear conditioning test seems to be more reliable.
As analyzed by Owen et al., contextual fear conditioning detected less variability across genotypes and thus appears to be more broadly applicable to studies of complex learning in mice compared to Morris water maze task [58].

Cerebral amyloid plaque load was only reduced in mice vaccinated at an early and not at a late stage of Alzheimer-like disease (Figs. 6d and 7c). This observation indicates that already existing amyloid $\beta$ plaques cannot be reduced through anti-C5a vaccination whereas initial deposition can be alleviated significantly by anti-C5a interference. Interestingly, Fonseca et al. found a reduction of amyloid plaque load in $\operatorname{Tg} 2576$ mice upon treatment with PMX205, a C5aR inhibitor, starting at the age of 12 months [22]. The difference between our study and previously presented data may be due to the different interference strategies. Specifically, treatment with small molecules, such as PMX205, may immediately be effective, whereas an active immunization approach using C5a-peptide vaccines takes at least 4-6 weeks to mount an appropriate antibody response.

The major advantage of an active immunotherapy vs. the application mAbs or small molecules however is that prolonged therapeutic effects can be easily achieved by booster immunizations (Fig. 3a) whereas $\mathrm{mAB}$ and small molecule therapy is linked to frequent treatments and mostly high costs.

All immunotherapeutic approaches which target selfproteins have to consider the issue of potential autoimmunity. Thus, a prerequisite of our peptide vaccines was to stimulate the humoral immune system and induce specific and effective antibodies against complement factor C5a without inducing target-specific $\mathrm{T}$ cells and thereby 
avoiding a potential autoimmune response with lifethreatening consequences. The proprietary AFFITOME ${ }^{\circ}$ technology favors the use of short epitope-specific peptides ( $<13$ aa) which do not bind to MHC class II molecules. Peptides (AFFITOPE's) become antigenic only when coupled to a carrier protein (e.g., KLH) which provides $\mathrm{T}$ helper cell epitopes. Thus, immunization with AFF1 and AFF2 induces an effective B cell response and concurrently circumvents target-specific CD4 T cell activation. However, peptides which exceed 7 amino acids potentially activate MHC class I-restricted CD8 positive T cells. Analysis by online available $\mathrm{T}$ cell epitope prediction algorithms did not predict any relevant $\mathrm{T}$ cell epitope for the anti-C5a peptides AFF1 and AFF2. These in silico data were further confirmed by in vivo immunization experiments where no abnormalities in terms of mortality, weight loss, sensory and motor functions, handling behavior, and contextual memory skills of wt mice treated with the C5a-peptide vaccines were observed (Fig. 2a-d). Therefore, C5a-peptide vaccines represent a safe and well-tolerated immunotherapy, which is able to elicit a specific and long lasting immune response against C5a (Figs. 1a and 3a) without any relevant cross-reactivity. Another safety aspect of our vaccination approach was to target only $\mathrm{C} 5 \mathrm{a}$ and not $\mathrm{C} 5$ or $\mathrm{C} 5 \mathrm{~b}$, in order to interfere only with a terminal detrimental component of the complement system. Potentially protective complement activation events more upstream important for the clearance of aggregated proteins and cell debris will be maintained [54].

We showed that $\mathrm{C}^{2} \mathrm{a}-\mathrm{AFFITOPE}^{\circ}$ vaccination is able to target the pro-inflammatory complement activation product $\mathrm{C} 5 \mathrm{a}$, thus preventing enhanced microglia activation in the hippocampus, reducing memory decline and $\mathrm{A} \beta$ pathology in a model of AD.

Thus, active immunotherapy against complement factor C5a is a new and effective approach for the treatment of $\mathrm{AD}$-like disease. Moreover, these promising results suggest a therapeutic potential of C5a vaccination not only in $\mathrm{AD}$ but also for other indications in which chronic inflammatory processes driven by complement activation may play a pivotal role.

\section{Competing interests}

All authors are employees of AFFiRiS, the company that commercializes the AFFITOPE's described in the manuscript.

\section{Authors' contributions}

BN carried out the immunohistochemical staining. $C L$ designed the studies, was responsible for the acquisition, analyses and interpretations of data, and drafted the manuscript. GS has made substantial contributions to conception and design, interpretation of data, and has revised the manuscript critically for important intellectual content. KY performed important ELISA and Western blot analyses. LO carried out the ELISA analyses and helped with the immunohistochemical staining. MM participated in the design of the studies and helped to interpret the data. PG set up and carried out the contextual fear conditioning test in mice. RS helped with the analyses of immunohistochemical data. All authors read and approved the final manuscript.

\section{Acknowledgements}

We thank Beate Pilz, Martina-Anna Gschirtz, and Markus Sonntagbauer for technical help and Michael Hierzer for the collection of CSF samples. Furthermore, we want to acknowledge Oleksandr Otava for his help with statistical analyses and Benjamin Vigl who provided his expertise in GraphPad analyses. We express our gratitude to Arne von Bonin for supervising the project and Lanay Tierney for proof reading the manuscript.

Received: 30 April 2015 Accepted: 27 July 2015

Published online: 16 August 2015

\section{References}

1. Baranello RJ, Bharani KL, Padmaraju V, Chopra N, Lahiri DK, Greig NH, et al. Amyloid-beta protein clearance and degradation (ABCD) pathways and their role in Alzheimer's disease. Curr Alzheimer Res. 2015;12:32-46.

2. Takashima A. Tauopathies and tau oligomers. J Alzheimers Dis. 2013:37:565-8.

3. Latta CH, Brothers HM, Wilcock DM. Neuroinflammation in Alzheimer's disease. A source of heterogeneity and target for personalized therapy. Neuroscience. 2014.

4. Hardy J, Allsop D. Amyloid deposition as the central event in the aetiology of Alzheimer's disease. Trends Pharmacol Sci. 1991;12:383-8.

5. Karran E, Mercken M, De Strooper B. The amyloid cascade hypothesis for Alzheimer's disease: an appraisal for the development of therapeutics. Nat Rev Drug Discov. 2011;10:698-712.

6. Doody RS, Thomas RG, Farlow M, Iwatsubo T, Vellas B, Joffe $\mathrm{S}$, et al. Phase 3 trials of solanezumab for mild-to-moderate Alzheimer's disease. N Engl J Med. 2014;370:311-21.

7. Aizenstein HJ, Nebes RD, Saxton JA, Price JC, Mathis CA, Tsopelas ND, et al. Frequent amyloid deposition without significant cognitive impairment among the elderly. Arch Neurol. 2008;65:1509-17.

8. Mathis CA, Kuller LH, Klunk WE, Snitz BE, Price JC, Weissfeld LA, et al. In vivo assessment of amyloid-beta deposition in nondemented very elderly subjects. Ann Neurol. 2013;73:751-61.

9. Blurton-Jones M, Kitazawa M, Martinez-Coria H, Castello NA, Muller FJ, Loring JF, et al. Neural stem cells improve cognition via BDNF in a transgenic model of Alzheimer disease. Proc Natl Acad Sci U S A. 2009;106:13594-9.

10. Heneka MT, Kummer MP, Latz E. Innate immune activation in neurodegenerative disease. Nat Rev Immunol. 2014;14:463-77.

11. Wyss-Coray T, Rogers J. Inflammation in Alzheimer disease-a brief review of the basic science and clinical literature. Cold Spring Harb Perspectives in Medicine. 2012;2:a006346.

12. Akiyama H, Barger S, Barnum S, Bradt B, Bauer J, Cole GM, et al. Inflammation and Alzheimer's disease. Neurobiol Aging. 2000;21:383-421.

13. Serrano-Pozo A, Muzikansky A, Gomez-Isla T, Growdon JH, Betensky RA, Frosch MP, et al. Differential relationships of reactive astrocytes and microglia to fibrillar amyloid deposits in Alzheimer disease. J Neuropathol Exp Neurol. 2013;72:462-71.

14. Fukumoto H, Asami-Odaka A, Suzuki N, Iwatsubo T. Association of A beta 40-positive senile plaques with microglial cells in the brains of patients with Alzheimer's disease and in non-demented aged individuals. Neurodegeneration. 1996;5:13-7.

15. Hensley K. Neuroinflammation in Alzheimer's disease: mechanisms, pathologic consequences, and potential for therapeutic manipulation. J Alzheimers Dis. 2010:21:1-14.

16. Doens D, Fernandez PL. Microglia receptors and their implications in the response to amyloid beta for Alzheimer's disease pathogenesis. J Neuroinflammation. 2014;11:48.

17. Loeffler DA, Camp DM, Bennett DA. Plaque complement activation and cognitive loss in Alzheimer's disease. J Neuroinflammation. 2008:5:9.

18. Shen Y, Halperin JA, Benzaquen L, Lee CM. Characterization of neuronal cell death induced by complement activation. Brain Res Brain Res Protoc. 1997;1:186-94

19. Orre M, Kamphuis W, Osborn LM, Jansen AH, Kooijman L, Bossers $K$, et al. Isolation of glia from Alzheimer's mice reveals inflammation and dysfunction. Neurobiol Aging. 2014;35:2746-60.

20. Ager RR, Fonseca MI, Chu SH, Sanderson SD, Taylor SM, Woodruff TM, et al. Microglial C5aR (CD88) expression correlates with amyloid-beta deposition in murine models of Alzheimer's disease. J Neurochem. 2010;113:389-401. 
21. Woodruff TM, Crane JW, Proctor LM, Buller KM, Shek AB, de Vos K, et al. Therapeutic activity of C5a receptor antagonists in a rat model of neurodegeneration. FASEB J. 2006;20:1407-17.

22. Fonseca MI, Ager RR, Chu SH, Yazan O, Sanderson SD, LaFerla FM, et al. Treatment with a C5aR antagonist decreases pathology and enhances behavioral performance in murine models of Alzheimer's disease. J Immunol. 2009;183:1375-83.

23. Ryman D, Gao Y, Lamb BT. Genetic loci modulating amyloid-beta levels in a mouse model of Alzheimer's disease. Neurobiol Aging. 2008;29:1190-8.

24. Hsiao K, Chapman P, Nilsen S, Eckman C, Harigaya Y, Younkin S, et al. Correlative memory deficits, Abeta elevation, and amyloid plaques in transgenic mice. Science. 1996;274:99-102.

25. Rustay NR, Cronin EA, Curzon P, Markosyan S, Bitner RS, Ellis TA, et al. Mice expressing the Swedish APP mutation on a 129 genetic background demonstrate consistent behavioral deficits and pathological markers of Alzheimer's disease. Brain Res. 2010;1311:136-47.

26. Schneeberger A, Mandler M, Mattner F, Schmidt W. AFFITOME(R) technology in neurodegenerative diseases: the doubling advantage. Hum Vaccin. 2010;6:948-52.

27. Mandler M, Rockenstein E, Ubhi K, Hansen L, Adame A, Michael S, et al. Detection of peri-synaptic amyloid-beta pyroglutamate aggregates in early stages of Alzheimer's disease and in AbetaPP transgenic mice using a novel monoclonal antibody. J Alzheimers Dis. 2012;28:783-94.

28. Lue LF, Walker DG, Brachova L, Beach TG, Rogers J, Schmidt AM, et al. Involvement of microglial receptor for advanced glycation endproducts (RAGE) in Alzheimer's disease: identification of a cellular activation mechanism. Exp Neurol. 2001;171:29-45.

29. Moore KJ, El Khoury J, Medeiros LA, Terada K, Geula C, Luster AD, et al. A CD36-initiated signaling cascade mediates inflammatory effects of beta-amyloid. J Biol Chem. 2002;277:47373-9.

30. Farkas I, Takahashi M, Fukuda A, Yamamoto N, Akatsu H, Baranyi L, et al. Complement C5a receptor-mediated signaling may be involved in neurodegeneration in Alzheimer's disease. J Immunol. 2003;170:5764-71.

31. Rogers J, Schultz J, Brachova L, Lue LF, Webster S, Bradt B, et al. Complement activation and beta-amyloid-mediated neurotoxicity in Alzheimer's disease. Res Immunol. 1992;143:624-30.

32. Szczepanik AM, Funes S, Petko W, Ringheim GE. IL-4, IL-10 and IL-13 modulate A beta(1-42)-induced cytokine and chemokine production in primary murine microglia and a human monocyte cell line. J Neuroimmunol. 2001;113:49-62.

33. Rosi S, Pert CB, Ruff MR, McGann-Gramling K, Wenk GL. Chemokine receptor 5 antagonist D-Ala-peptide T-amide reduces microglia and astrocyte activation within the hippocampus in a neuroinflammatory rat model of Alzheimer's disease. Neuroscience. 2005;134:671-6.

34. Szczepanik AM, Rampe D, Ringheim GE. Amyloid-beta peptide fragments p3 and $\mathrm{p} 4$ induce pro-inflammatory cytokine and chemokine production in vitro and in vivo. J Neurochem. 2001;77:304-17.

35. McGeer EG, McGeer PL. Neuroinflammation in Alzheimer's disease and mild cognitive impairment: a field in its infancy. J Alzheimers Dis. 2010;19:355-61.

36. Veerhuis R, Janssen I, De Groot CJ, Van Muiswinkel FL, Hack CE, Eikelenboom P. Cytokines associated with amyloid plaques in Alzheimer's disease brain stimulate human glial and neuronal cell cultures to secrete early complement proteins, but not C1-inhibitor. Exp Neurol. 1999;160:289-99.

37. Li J, Yang JY, Yao XC, Xue X, Zhang QC, Wang XX, et al. Oligomeric Abeta-induced microglial activation is possibly mediated by NADPH oxidase. Neurochem Res. 2013;38:443-52.

38. Sochocka M, Koutsouraki ES, Gasiorowski K, Leszek J. Vascular oxidative stress and mitochondrial failure in the pathobiology of Alzheimer's disease: a new approach to therapy. CNS Neurol Disord Drug Targets. 2013;12:870-81.

39. Busche MA, Eichhoff $G$, Adelsberger $H$, Abramowski D, Wiederhold KH, Haass $C$, et al. Clusters of hyperactive neurons near amyloid plaques in a mouse model of Alzheimer's disease. Science. 2008;321:1686-9.

40. Brandenburg LO, Konrad M, Wruck CJ, Koch T, Lucius R, Pufe T. Functional and physical interactions between formyl-peptide-receptors and scavenger receptor MARCO and their involvement in amyloid beta 1-42-induced signal transduction in glial cells. J Neurochem. 2010;113:749-60.

41. Del Bo R, Angeretti N, Lucca E, De Simoni MG, Forloni G. Reciprocal control of inflammatory cytokines, IL-1 and IL-6, and beta-amyloid production in cultures. Neurosci Lett. 1995;188:70-4.
42. Feng $Y$, Li L, Sun XH. Monocytes and Alzheimer's disease. Neurosci Bull. 2011;27:115-22.

43. Hickman SE, Allison EK, El Khoury J. Microglial dysfunction and defective beta-amyloid clearance pathways in aging Alzheimer's disease mice. J Neurosci. 2008;28:8354-60.

44. Misonou H, Morishima-Kawashima M, Ihara Y. Oxidative stress induces intracellular accumulation of amyloid beta-protein (Abeta) in human neuroblastoma cells. Biochemistry. 2000;39:6951-9.

45. Ringheim GE, Szczepanik AM, Petko W, Burgher KL, Zhu SZ, Chao CC. Enhancement of beta-amyloid precursor protein transcription and expression by the soluble interleukin- 6 receptor/interleukin- 6 complex. Brain Res Mol Brain Res. 1998;55:35-44.

46. Rahpeymai Y, Hietala MA, Wilhelmsson U, Fotheringham A, Davies I, Nilsson AK, et al. Complement: a novel factor in basal and ischemia-induced neurogenesis. EMBO J. 2006;25:1364-74.

47. Brennan FH, Anderson AJ, Taylor SM, Woodruff TM, Ruitenberg MJ. Complement activation in the injured central nervous system: another dual-edged sword? J Neuroinflammation. 2012;9:137.

48. Rutkowski MJ, Sughrue ME, Kane AJ, Mills SA, Fang S, Parsa AT. Complement and the central nervous system: emerging roles in development, protection and regeneration. Immunol Cell Biol. 2010;88:781-6

49. Woodruff TM, Ager RR, Tenner AJ, Noakes PG, Taylor SM. The role of the complement system and the activation fragment C5a in the central nervous system. Neuromolecular Med. 2010;12:179-92.

50. Mukherjee P, Pasinetti GM. Complement anaphylatoxin C5a neuroprotects through mitogen-activated protein kinase-dependent inhibition of caspase 3. J Neurochem. 2001;77:43-9.

51. Mukherjee P, Thomas S, Pasinetti GM. Complement anaphylatoxin C5a neuroprotects through regulation of glutamate receptor subunit 2 in vitro and in vivo. J Neuroinflammation. 2008;5:5.

52. Osaka H, Mukherjee P, Aisen PS, Pasinetti GM. Complement-derived anaphylatoxin C5a protects against glutamate-mediated neurotoxicity. J Cell Biochem. 1999;73:303-11.

53. Persson M, Pekna M, Hansson E, Ronnback L. The complement-derived anaphylatoxin C5a increases microglial GLT-1 expression and glutamate uptake in a TNF-alpha-independent manner. Eur J Neurosci. 2009;29:267-74.

54. Benoit ME, Hernandez MX, Dinh ML, Benavente F, Vasquez O, Tenner AJ. C1q-induced LRP1B and GPR6 proteins expressed early in Alzheimer disease mouse models, are essential for the C1q-mediated protection against amyloid-beta neurotoxicity. J Biol Chem. 2013;288:654-65.

55. Fu H, Liu B, Frost JL, Hong S, Jin M, Ostaszewski B, et al. Complement component $\mathrm{C} 3$ and complement receptor type 3 contribute to the phagocytosis and clearance of fibrillar Abeta by microglia. Glia. 2012;60:993-1003.

56. Perry $\mathrm{VH}$. The influence of systemic inflammation on inflammation in the brain: implications for chronic neurodegenerative disease. Brain Behav Immun. 2004;18:407-13.

57. Perry $\mathrm{VH}$, Holmes C. Microglial priming in neurodegenerative disease. Nat Rev Neurol. 2014;10:217-24.

58. Owen EH, Logue SF, Rasmussen DL, Wehner JM. Assessment of learning by the Morris water task and fear conditioning in inbred mouse strains and F1 hybrids: implications of genetic background for single gene mutations and quantitative trait loci analyses. Neuroscience. 1997:80:1087-99. 